\title{
Predicting disease occurrence of cabbage Verticillium wilt in monoculture using species distribution modeling
}

\author{
Kentaro Ikeda ${ }^{\text {Corresp., } 1}$, Takeshi Osawa ${ }^{2}$ \\ ${ }^{1}$ Department of Agriculture, Gunma Prefectural Office, Isesaki, Gunma, Japan \\ ${ }^{2}$ Faculty of Urban Environmental Science, Tokyo Metropolitan University, Hachioji, Tokyo, Japan \\ Corresponding Author: Kentaro Ikeda \\ Email address: ikeda-ken@pref.gunma.Ig.jp
}

Background Although integrated pest management (IPM) is essential for conservation agriculture, this method can be inadequate for severely infected fields. The ability to predict the potential occurrence of severe infestation of soil-borne disease would enable farmers to adopt suitable methods for high-risk areas, such as soil disinfestation, and apply other options for lower risk areas. Recently, researchers have used species distribution modeling (SDM) to predict the occurrence of target plant and animal species based on various environmental variables. In this study, we applied this technique to predict and map the occurrence probability of a soil-borne disease, Verticillium wilt, using cabbage as a case study.

Methods A disease survey assessing the distribution of Verticillium wilt in cabbage fields in Tsumagoi village (central Honshu, Japan) was conducted two or three times annually from 1997 to 2013. Road density, elevation and topographic wetness index (TWI) were selected as explanatory variables for disease occurrence potential. A model of occurrence probability of Verticillium wilt was constructed using the MaxEnt software for SDM analysis. As the disease survey was mainly conducted in an agricultural area, the area was weighted as "Bias Grid" and area except for the agricultural area was set as background.

Results Grids with disease occurrence showed a high degree of coincidence with those with a high probability occurrence. The highest contribution to the prediction of disease occurrence was the variable road density at $97.1 \%$, followed by TWI at $2.3 \%$, and elevation at $0.5 \%$. The highest permutation importance was road density at $93.0 \%$, followed by TWI at $7.0 \%$, while the variable elevation at $0.0 \%$. This method of predicting disease probability occurrence can help with disease monitoring in areas with high probability occurrence and inform farmers about the selection of control measures. 


\section{Predicting disease occurrence of cabbage Verticillium}

2 wilt in monoculture using species distribution

3 modeling

4

5

6

7

8 9

10

11

12

13

14

15

16

17

Kentaro Ikeda ${ }^{1}$, Takeshi Osawa ${ }^{2}$

${ }^{1}$ Department of Agriculture, Gunma Prefectural Office, Isesaki, Gunma, Japan

${ }^{2}$ Faculty of Urban Environmental Science, Tokyo Metropolitan University, Hachioji, Tokyo, Japan

Corresponding Author:

Kentaro Ikeda ${ }^{1}$

Nishi-Obokata 493, Isesaki, Gunma, 379-2224, Japan

Email address: ikeda-ken@pref.gunma.lg.jp

\section{Abstract}

\section{Background}

Although integrated pest management (IPM) is essential for conservation agriculture, this method can be inadequate for severely infected fields. The ability to predict the potential occurrence of severe infestation of soil-borne disease would enable farmers to adopt suitable methods for high-risk areas, such as soil disinfestation, and apply other options for lower risk areas. Recently, researchers have used species distribution modeling (SDM) to predict the occurrence of target plant and animal species based on various environmental variables. In this study, we applied this technique to predict and map the occurrence probability of a soil-borne disease, Verticillium wilt, using cabbage as a case study.

\section{Methods}

A disease survey assessing the distribution of Verticillium wilt in cabbage fields in Tsumagoi village (central Honshu, Japan) was conducted two or three times annually from 1997 to 2013. Road density, elevation and topographic wetness index (TWI) were selected as explanatory variables for disease occurrence potential. A model of occurrence probability of Verticillium wilt was constructed using the MaxEnt software for SDM analysis. As the disease survey was mainly conducted in an agricultural area, the area was weighted as "Bias Grid" and area except for the agricultural area was set as background.

\section{Results}

Grids with disease occurrence showed a high degree of coincidence with those with a high probability occurrence. The highest contribution to the prediction of disease occurrence was the 
40 variable road density at $97.1 \%$, followed by $T W I$ at $2.3 \%$, and elevation at $0.5 \%$. The highest

41 permutation importance was road density at $93.0 \%$, followed by $T W I$ at $7.0 \%$, while the variable

42 elevation at $0.0 \%$. This method of predicting disease probability occurrence can help with

43 disease monitoring in areas with high probability occurrence and inform farmers about the

44 selection of control measures.

45

46

\section{Introduction}

48

49

50

51

52

53

54

55

56

57

58

59

60

61

62

63

64

65

66

67

68

69

70

71

72

73

74

75

76

77

78

79

Intensive agriculture has supported world food production since World War II (Moffatt 2020). However, the sustainability of intensive agriculture is often questioned because of negative consequences such as soil and water pollution, risks to human health from pesticides and fertilizer, and water resource depletion by over-exploitation of water resources (Oosterbaan 1989; Matson et al. 1997; Tilman et al. 2002; Hernández et al. 2006). To address these problems, a shift to conservation agriculture is required (Reicosky 2003; Kassam et al. 2009). On the other hand, measures to increase food supply to maintain food security are also needed because the world population is expected to reach over 9.7 billion by 2050 (United Nations 2015). These competing demands for sustainability and higher yields presents a complex problem facing modern intensive agriculture (Brussaard et al. 2010), but it is a challenge that must be met.

To cope with the ever growing global food demand, intensive agriculture primarily revolves around large-scale monoculture, the continuous or consecutive growth of the same crop over large areas (Cook and Weller, 2004). Monocultures carry a heavy risk of soil-borne disease because pathogens have a continuous supply of host plant and are thus able to persist or even accumulate in the soil (Newton et al. 2009; Jenking et al. 2010). Soil disinfestation by fumigation with chemical control agents can be effective in the management of soil-borne disease (Wilhelm and Paulus 1980; Koike et al. 2003), but also carries the risk of negative impacts on the environment and human health (Hernández et al. 2006; Sande et al. 2011; United States Environmental Protection Agency 2017). In addition, as more fields require chemical control, the costs associated therewith also increase (Landis 1987; Labrada et al. 2001; Koike et al. 2006). So, although effective, chemical disinfestation to reduce soil-borne disease can be difficult to adopt when the costs and consequences outweigh the benefits.

Integrated pest management (IPM), which is defined as the long-term prevention of pests or their damage through a combination of techniques, is essential for sustainable agriculture (Apple et al. 1976, UC IPM 2020). The control of soil-borne disease in IPM typically involves the application of resistant cultivars, crop rotation, exclusion and prevention of pathogen's inoculum source (Tsushima 2014; Ikeda et al. 2015). However, such methods are inadequate to bring about control in severely infested fields. Therefore, intensive continuous soil fumigation may be justified in severely infested fields (Krikun et al. 1974). If the potential occurrence of severe infection of soil-borne disease could be predicted, farmers could adopt soil fumigation for high- 
80 risk areas and apply other options for areas of lower risk. Furthermore, evaluating infestation risk 81 in a giving area can help growers to prevent the spread to unaffected fields or re-introduction in 82 previously managed fields. This approach is in accordance with the IPM framework for 83 sustainable, low-environmental impact, and cost-effective agriculture (Tsushima and Yoshida 84 2012). Control measures for soil-borne diseases should be selected according to the disease 85 potential occurrence of each target area. However, the development of a practical method to 86 predict such disease potential occurrence has not previously been given in the field of plant 87 pathology.

88

Ecological science uses species distribution modeling (SDM) (e.g. Osawa 2011; Osawa 2015) 90 animal species based on environmental variables such as terrain and climate factors (Guisan and Zimmermann 2000; Soberón and Peterson 2005; Soberón J. 2007; Peterson et al. 2011; Peterson 2014). SDM can predict the distribution of a target species using survey data obtained in the area (McCune 2016). Additionally, the respective contribution, or importance, of environmental variables on species distribution can be calculated. Maximum entropy algorithm is one of the most famous SDM approaches and can be used to predict species potential distribution by analyzing presence-only data with environmental variables (Phillips et al. 2004; Phillips et al. 2006). MaxEnt software has been successfully used in predicting potential species distribution (Ortega-Huerta et al. 2008). Recently, MaxEnt has been used to predict plant disease distribution, such as Fusarium dry root rot in common beans, Phomopsis vaccinii in Vaccinium species, myrtle rust in Myrtaceae family and Pseudomonas syringae pv. actinidiae in kiwifruit (Cunniffe et al. 2016; Macedo et al. 2017; Narouei-Khandan et al. 2017; Berthon et al. 2018; Wang et al. 2018; Narouei-Khandan et al. 2020). In the present study, we used MaxEnt to predict the occurrence probability of Verticillium wilt, a soil-borne disease, as a case study on cabbage field in Japan.

Tsumagoi village in the Gunma prefecture of Japan intensively produces cabbage as one of the main production sites for this crop in Japan. This is an ideal site to test the application of the SDM technique, given its large-scale area of consolidated monoculture and years of field monitoring, which enable a detailed analysis of the occurrence of Verticillium wilt. Verticillium wilt in cabbage has been a big problem in this region's cabbage production since 1994 (Shiraishi et al., 2000). This is a soil-borne disease caused by Verticillium dahliae and $V$. longisporum (Banno et al., 2011). The cabbage farmers in Tsumagoi village have suffered severe economic losses from this disease (Shiraishi et al. 2000).

The objective of the study was to construct an occurrence probability map of Verticillium wilt of cabbage in Tsumagoi village in Gunma prefecture in Japan to test the application of SDM to soilborne plant disease. The findings aim to inform farmers to choose adequate control measures, such as introducing resistant cultivars or changing cultivation period. This trial can contribute to 
120 the development of IPM by offering both environmental and economic improvements to soil-

121

122

123

124

125

126

127

128

129

130

131

132

133

134

135

136

137

138

139

140

141

142

143

144

145

146

147

148

149

150

151

152

153

154

155

156

157

158

159

borne disease management in agricultural production.

\section{Materials \& Methods Study area}

The distribution of Verticillium wilt of cabbage was surveyed in Tsumagoi village (36 $51^{\circ} 17^{\prime \prime} \mathrm{N}$, $138^{\circ} 53^{\prime} 00^{\prime \prime E}$ ) in central Honshu, the largest of Japan's four main islands (Fig. 1). The climate is subarctic humid climate (Dfb) in Köppen climate classification with an elevation ranging between 700 and $1500 \mathrm{~m}$ above sea level and a mean annual temperature of $7.2^{\circ} \mathrm{C}$ (Japan Meteorological Agency 2017, Village Office of Tsumagoi 2017). Cabbages are produced on approximately 2790 ha of the 3200 ha agricultural area. This is a remarkably large monoculture site for cabbage production in Japan. Thus, the village is renowned in Japan as a production site for cabbage. Cabbages are harvested there from April (early spring) to October (autumn) (Village Office of Tsumagoi 2017). However, potato, maize and scarlet runner bean are also grown in this area, in significantly lower proportions than those of cabbage (Village Office of Tsumagoi 2017).

\section{Target disease and disease survey}

Cabbage production in the area has suffered from Verticillium wilt since 1994 (Shiraishi et al. 2000). Verticillium wilt is a soil-borne disease associated with Verticillium dahliae and $V$. longisporum (Banno et al. 2011), which can survive for years using microsclerotia as a resting structure. $V$. dahliae has a board range of hosts, mainly plants from the Solanaceae and Brassicaceae families (Pegg and Brady, 2002), while $V$. longisporum infects mainly members of the Brassicaceae family (Inderbitzin et al., 2013). In our study site, $V$. dahliae was found to be the dominant species causing Vertillium wilt in cabbage (Banno et al., 2015). In recent years, cultivars resistant to Verticillium wilt have been planted in the village. The disease survey was conducted two or three times per year annually from 1997 to 2013, 38 times in total by official and private agricultural extension workers and plant pathologists capable of distinguishing the disease in all fields of the village. This survey and field collections were approved by Gunma Prefectural Office under permission document no. H28.114.30. Disease occurrence was identified by external symptoms such as outer leaf yellowing and wilting (Fig. 2A, B). When a cabbage suspected to be infected was found, the observers examined the vascular system of selected cabbages to identify browning and thus confirm the existence of the disease (Fig. 2C). The locations of fields where the disease occurred in field survey were marked on a 1:5000 map. When new records were found, investigators took cabbage samples for isolation and identification of the pathogens. The study area was divided into a grid of $500 \times 500 \mathrm{~m}$ cells. The grid cell size was selected according to both the degree of accuracy of the disease survey and the scale of land ownership. Disease occurrence (a binary variable) of both pathogen species and the values of the selected explanatory variables were recorded for each grid cell (Fig. 3A, B).

Peer) reviewing PDF | (2020:03:46741:2:0:NEW 19 Sep 2020) 
160

161

162

163

164

165

166

167

168

169

170

171

172

173

174

175

176

177

178

179

180

181

182

183

184

185

186

187

188

189

190

191

192

193

194

195

196

197

198

199

\section{Explanatory variables}

Geographic Information System software ArcMap (ver. 10.7.1, ESRI, Redlands, CA, USA) was used for analysis of the data set. We selected road density, elevation and topographic wetness index (TWI) as possible explanatory variables that may affect the disease potential occurrence. In Tsumagoi village, the pathogens of cabbage Vertillium wilt were detected in field soil (Banno et al. 2011) and there was serious soil erosion from cabbage fields to the roads (Deb 2006). This suggested to us that the disease spread from one field to another by pathogen-infested soil, which prompted us to investigated road density as an explanatory variables. Furthermore, we included elevation as an explanatory variables because of relationship between elevation and temperature: for every $100 \mathrm{~m}$ increase in elevation, temperature rises by about $0.6^{\circ} \mathrm{C}$. Finally, we also selected TWI, which indicates the degree of soil moisture (Gallant 2000), the latter is known to influence the development of soil-borne disease like Verticillium wilt (Pegg and Brady, 2002). Road data were downloaded as polyline data from Fundamental Geospatial Data (Geographical Survey Institute; http:/www.gsi.go.jp/kiban/, accessed on 24 June 2020). The number of new roads had not increased dramatically from 2013 to 2016 in the study area. The total length of road in each grid cell was calculated from the polyline data as "road density." Elevation and slope were downloaded from the National Land Numerical Information download service (Ministry of Land, Infrastructure, Transport and Tourism, http://nlftp.mlit.go.jp/ksj/, accessed on 24 June 2020). Slope data are required to calculate TWI (Gallant 2000), which is defined as follows:

$$
\mathrm{TWI}=\ln \frac{a}{\tan b}
$$

where $a$ is local catchment area (i.e., the local upslope area draining per unit) and $b$ is the local slope. Values for elevation and TWI were applied to each grid cell along with the road density variable. The agricultural area shown in Fig. 3A were also downloaded from the National Land Numerical Information download service described above.

\section{Model construction}

The model of probability of disease occurrence was constructed using SDM software MaxEnt ver. 3.3.3k (downloaded at: https://biodiversityinformatics.amnh.org/open_source/maxent/) (Phillips et al. 2004; Phillips et al. 2006). This software was chosen as it can analyze presenceonly data efficiently with a low number of occurrences (Elith 2006). MaxEnt is used for predicting habitat suitability of target species, but here we applied it to the prediction of probability of soil-borne disease occurrence. The disease occurrence probability (0-1) in each grid cell, percent contribution and permutation importance of each explanatory variables were calculated by MaxEnt. We conducted the analysis using the whole village area, given that this was the scale relevant for our study. However, the original disease survey was mainly conducted within the agricultural areas (Figure 3A), hence we used a "Bias Grid" weighting and set the remaining "non-agricultural area" as background in MaxEnt setting. To avoid overfitting, only "Liner" and "Quadractic" functions were used and the value for "Regularization multiplier" was changed from " 1 " to " 2 " in MaxEnt settings (Merow et al., 2013; Radosavlijevic and Adnderson, 
200

201

202

203

204

205

206

207

208

209

210

211

212

213

214

215

216

217

218

219

220

221

222

223

224

225

226

227

228

229

230

231

232

233

234

235

236

237

238 Our result showed that road density significantly influenced disease occurrence probability 239

2014; Syfert et al., 2013). Cross-validation was selected in "Replicated run type" and repeated 20 times. The model of the probability of disease occurrence was also estimated by means of receiver operating characteristic (ROC) analysis. Furthermore, correctly classified instances (CCI), sensitivity, specificity, true skill statistics (TSS) were calculated based on the "threshold by maximum training sensitivity plus specificity" in MaxEnt to evaluate model performance.

\section{Results}

There were 1392 grids cells in our study area, we confirmed disease occurrence in 194 grid cells (Fig. 3B). The SDM model constructed with MaxEnt was used to map the probability of disease occurrence and points of disease occurrence (Fig. 4). Threshold by Maximum training sensitivity plus specificity from MaxEnt analysis was 0.543 . The disease occurrence probability map was created based on this threshold. Grids in this map were colored when the grids had a higher probability compared to the threshold (in total, 556 / 1392 grids in this study area). The grids with disease occurrence had a high degree of coincidence with those with a high probability of such occurrence.

Percent contribution and permutation importance of predictor variables are shown in Table 1. The highest contribution to the prediction was road density at $97.1 \%$, followed by TWI at $2.3 \%$, and elevation at $0.5 \%$. Permutation importance was as follow: road density at $93.0 \%$, TWI at $7.0 \%$, and elevation at $0.0 \%$. Both percent contribution and permutation importance indicated that road density was the best predictor variable: disease probability occurrence was highest when road density was about $4000 \mathrm{~m} /$ grid (Fig. 5).

Estimation indices for accuracy of MaxEnt modeling of cabbage Verticillium wilt is shown in Table 2. The constructed model represented the occurrence of Verticillium wilt of cabbage moderately well, as demonstrated by the value, 0.861 , of the AUC average of the ROC. The calculated values for CCI, sensitivity, specificity, and TSS using the threshold were $0.705,0.876$, 0.678 and 0.544 , respectively.

\section{Discussion}

In this study, we applied SDM to predict the occurrence probability of Verticillium wilt in cabbage as a case study. Our model could provide the occurrence of Verticillium wilt of cabbage in Tsumagoi village to some degree. To the best of our knowledge, this is the first time SDM has been used to estimate occurrence probability of soil-borne disease. Our findings indicated that this method can successfully predict disease occurrence probability using survey data and selected environmental variables in a monoculture area. (Table 1), with the highest probability of disease at around $4000 \mathrm{~m} /$ grid (Fig. 5). Numminen and 
240 Laine (2020) showed that road networks played an important role in the spread of plant diseases, 241 which is consistent with our findings, suggested that the pathogen spread via road networks. It 242 was thought that the pathogen was locally transmitted between fields through the soil, as they are 243 soil-borne (Banno et al. 2011). Soil can be transferred from infested fields to road surfaces on the 244 wheels of tractors or other vehicles and even the footwear of farmworkers. Additionally,

245 Tsumagoi village is located in mountainous area with steep slopes, which facilitates soil transfer 246 between fields (e.g., by wind and water). Both natural and human-mediated processes can 247 influence the spread of Verticillium wilt in our study area.

248

249

250

251

252

253

254

255

256

257

258

259

260

261

262

263

264

265

266

267

268

269

270

271

272

273

274

275

276

277

278

279

On the other hand, our model suggested that the influence of TWI was quite low, even though soil moisture has previously been known to influence the development of soil-borne disease like Verticillium wilt (Pegg and Brady, 2002). The relationship between Verticillium wilt in cabbage and soil moisture had not yet been investigated before this study; however, it was reported that soil moisture was not significant factor for disease development in oilseed rape, Brassicaceae family (Knüfer, 2013). Consequently, the low impact shown by TWI on disease occurrence probability concurs with previous research, although more research is required to conclusively rule out this relationship. Elevation also showed a very low contribution to the probability of disease occurrence. In general, there are a correlation between elevation and temperature, as temperature rises about $0.6^{\circ} \mathrm{C}$ for every $100 \mathrm{~m}$ increase in elevation. Given that the optimal temperature for cabbage Verticillium wilt was between $19^{\circ} \mathrm{C}$ and $23^{\circ} \mathrm{C}$, temperature during the harvest period is regarded as an especially important (Kemmochi et al 2001). Therefore, we predicted that elevation could have an influence on disease occurrence. Cabbage is normally cultivated between 4 and $24^{\circ} \mathrm{C}$ (Bradley and Courtier, 2006). Cabbage cultivation period was determined according to the elevation of each field because temperature decreases with increasing elevation. Given our results, the elevation factor might not influence the probability of disease occurrence in our study area.

Our model was evaluated using statistic metrics based on the defined threshold (Table 2) and the disease occurrence probability map (Fig. 4). It appeared that many grids where disease occurrence was recorded had a high probability. However, the AUC, CCI, sensitivity, specificity and TSS obtained from our analysis were moderate compared with other studies (Wang et al. 2018; Narouei-Khandan et al., 2020). The sensitivity of the model should be regarded as the most important for our objective because we hope use it to monitor grids with a high disease occurrence probability. The sensitivity of the constructed model was 0.88 , which indicates that the model can predict the disease occurrence grids at about $88 \%$ accuracy. As a result, the model constructed using MaxEnt was sufficiently effective for prediction of the disease occurrence.

The disease occurrence probability map helps disease monitoring in high probability grids and selected area, and can inform the application of measures such as fumigation, planting diseaseresistant cultivars, and changing the timing of cabbage cultivation (Kemmochi et al. 2001).

Peer) reviewing PDF | (2020:03:46741:2:0:NEW 19 Sep 2020) 
280

281

282

283

284

285

286

287

288

289

290

291

292

293

294

295

296

297

298

299

300

301

302

303

304

305

306

307

308

309

310

311

312

313

314

315

316

317

Although it is not possible to change the road density, it is possible to apply soil erosion and sediment transport control technologies such as the establishment of cover crops (Lawson et al. 2015) to decrease the potential occurrence of the disease, especially in those grid cells where there are preexisting records and those grid cells predicted to have high occurrence probability. In addition, we recommend that the farmers and extension workers apply methods to reduce potential spread of infested soil, such as using portable vehicle-washing equipment and changing footwear at the site are required.

This study shows that SDM analysis using MaxEnt can be used to predict the occurrence using survey data and environmental variables. This approach could be applied to other intensive crop cultivation areas with accurate disease survey data and environmental variables, available as GIS data, that potentially influence disease occurrence.

\section{Conclusions}

In this study, we applied SDM to predict the occurrence probability of Verticillium wilt of cabbage, soil-borne plant disease. The SDM model constructed from three explanatory variables provided prediction of the occurrence of Verticillium wilt of cabbage in Tsumagoi village, Japan. The model developed from the field survey data showed that road density played an important roles in the occurrence of the disease. Key points of this study are; 1) SDM enabled us to predict the probability of disease occurrence in a relatively narrow area; 2) potential explanatory variables for disease occurrence were predicted based on SDM using field survey; and 3) predicting the probability of disease occurrence can help farmers to select suitable control methods for high and low-risk areas.

\section{Acknowledgements}

This work was supported in part by a grant from the Science and Technology Research Promotion Program for Agriculture, Forestry, Fisheries and Food Industry (25056C) from the Ministry of Agriculture, Forestry and Fisheries, Gunma New Agricultural Frontier Fund from Gunma Prefectural Government and JSPS KAKENHI Grant Number 16H05061. We are also grateful to Shigenobu Yoshida, Seiya Tsushima, Hiroshi Sakai, Toshihiko Urushibara, Toshimasa Shiraishi, and extension workers of Japan Agricultural Corporative of Tsumagoi for their useful advice and technical support.

\section{References}

Apple, J. L., Ray, F., Smith, R.F. 1976. Integrated Pest Management. New York: Springer US 
318 Banno, S., Saito, H., Sakai, H., Urushibara, T., Ikeda, K., Kabe, T., Kemmochi, I., Fujimura, M.

319

320

321

322

323

324

325

326

327

328

329

330

331

332

333

334

335

336

337

338

339

340

341

342

343

344

345

346

347

348

349

350

351

352

353

354

355

356

357 2011. Quantitative nested real-time PCR detection of Verticillium longisporum and $V$. dahliae in the soil of cabbage fields. Journal of General Plant Pathology 77: 282-291. Banno, S., Ikeda, K., Saito, H., Sakai, H., Urushibara, T., Shiraishi, T., Fujimura, M. 2015. Characterization and distribution of two subtypes of Verticillium longisporum isolated from cabbage fields in Japan. Journal of General Plant Pathology, 81: 118-126.

Berthon, K., Esperon-Rodriguez, M., Beaumont, L. J., Carnegie, A. J., Leishman, M. R. 2018. Assessment and prioritization of plant species at risk from myrtle rust (Austropuccinia psidii) under current and future climates in Australia. Biological Conservation. 218:154162.

Bradley, F. M., Courtier, J. 2006. Vegetable gardening: from planting to picking - the complete guide to creating a bountiful garden hardcover, Readers Digest, New York, U.S.

Brussaard, L., Caron, P., Campbell, B.M., Lipper, L., Mainka, S., Rabbinge, R., Babin, D., Pulleman M. 2010. Reconciling biodiversity conservation and food security: scientific challenges for a new agriculture. Current Opinion in Environmental Sustainability 2: 3442.

Cook, R. J., Weller, D.M. 2004. In defense of crop monoculture. "New directions for a diverse planet." Proceedings of the 4th International Crop Science Congress, 26 Sep-1 Oct 2004, Brisbane, Australia.

Cunniffe, N.J., Richard, C.C., Meentemeyer, R.K., Rizzo, D.M., Gilligan, C.A. 2016. When, where, and whether to manage a plant epidemic. Proceedings of the National Academy of Sciences 113: 5640-5645.

Deb, S.K. 2006. Soil water movement in a uniform hillslope layered with traffic pan. University of Tokyo Thesis.

Elith, J., Graham, C.H., Anderson, R.P., Dudık, M., Ferrier, S., Guisan, A., Hijmans, R.J., Huettmann, F., Leathwick, J.R., Lehmann, A., Li, J., Lohmann, L.G., Loiselle, B.A., Manion, G., Moritz, C., Nakamura, M., Nakazawa, Y., McC. Overton, J., Peterson, A.T., Phillips, S.J., Richardson, K.S., Scachetti-Pereira, R., Schapire, R.E., Sobero'n J, Williams, S., Wisz, M.S., Zimmermann, N.E. 2006. Novel methods improve prediction of species' distributions from occurrence data. Ecography 29: 129-151.

Food and Agriculture Organization of the United Nations. 1955. The State of Food and Agriculture 1955: Review of a Decade and Outlook. Rome, Italy.

Gallant, J. 2000 Terrain Analysis: Principles and Applications. New York: John Wiley \& Sons Inc.

Guisan, A., Zimmermann, N.E. 2000 Predictive habitat distribution models in ecology. Ecological Modelling 135: 147-186.

Hernández, A.F., Amparo Gómez, M., Pérez, V., García-Lario, J.V., Pena, G., Gil, F., López O, Rodrigo, L., Pino, G., Pla, A. 2006. Influence of exposure to pesticides on serum components and enzyme activities of cytotoxicity among intensive agriculture farmers. Environmental Research 102: 70-76. 
358

359

360

361

362

363

364

365

366

367

368

369

370

371

372

373

374

375

376

377

378

379

380

381

382

383

384

385

386

387

388

389

390

391

392

393

394

395

396

397

Inderbitzin, P., Davis, R.M., Bostock, R.M., Subbarao, K.V. 2013. Identification and differentiation of Verticillium species and $V$. longisporum lineages by simplex and multiplex PCR assays. PloS one, 8.6, e65990.

Ikeda, K., Banno, S., Furusawa, A., Shibata, S., Nakaho, K., Fujimura, M. 2015. Crop rotation with broccoli suppresses Verticillium wilt of eggplant. Journal of General Plant Pathology 81: 77-82.

Japan Meteorological Agency. 2017. Precipitation database. Retrieved24 June 2020, from http://www.jma.go.jp/jma/menu/menureport.html.

Jenking, R., Jain, C.K. 2010. Advances in Soil-borne Plant Disease. Jaipur: Oxford Book Company

Kassam, A., Friedrich, T., Shaxson, F., Pretty, J. 2009. The spread of conservation agriculture: justification, sustainability and uptake. International Journal of Agricultural Sustainability 7: 292-320.

Kemmochi, I., Shisida, Y., Sakai, H., Honma, M., Shiraishi, T., Kobayashi, I., Machida, N. 2001. Factors influencing occurrence of verticillium wilt of cabbage and its agrotechnical control. (In Japanese with English summary) Gunma Horicultural Experimental Station Reports 6: 79-101.

Koike, S.T., Subbarao, K.V., Davis, R.M., Turini, T.A. 2003. Vegetable disease caused by soilborne pathogens. Retrieved 17 August, 2017, from http://anrcatalog.ucdavis.edu.

Koike, S,T., Gladders, P., Paulus, A. 2006. Vegetable diseases: A colour handbook. CRC Press; Boca Raton, Florida, U.S.

Knüfer, J. 2013. Improvement of Winter Oilseed Rape Resistance to Verticillium longisporumAssessment of Field Resistance and Characterization of Ultrastructural Plant Responses (Doctoral dissertation, Niedersächsische Staats-und Universitätsbibliothek Göttingen).

Krikun, J., Netzer, D., Sofer, M.1974. The role of soil fumigation under conditions of intensive agriculture. Agro-Ecosystems 1: 117-122.

Labrada, R., Fornasari, L. 2001. Global report on validated alternatives to the use of methyl bromide for soil fumigation. Retrieved 18 June, 2020, https://www.unenvironment.org/resources/report/global-report-validated-alternatives-usemethyl-bromide-soil-fumigation

Landis, T.D. 1987. Proceedings, Combined Western Forest Nursery Council and Intermountain Nursery Association Meeting, Fort Collins, Colo. U.S.

Lawson, A., Cogger, C., Bary, A., Fortuna, A. 2015. Influence of seeding ratio, planting date, and termination date on rye-hairy vetch cover crop mixture performance under organic management. PLoS ONE 10.6, e0129597.

McCune, J.L. 2016. Species distribution models predict rare species occurrences despite significant effects of landscape context. Journal of Applied Ecology 53: 1871-1879.

Macedo, R., Sales, L.P., Yoshida, F., Silva-Abud, L.L., Lobo, M.J. 2017. Potential worldwide distribution of Fusarium dry root rot in common beans based on the optimal environment for disease occurrence. PLoS ONE 12.11, e0187770. 
398

399

400

401

402

403

404

405

406

407

408

409

410

411

412

413

414

415

416

417

418

419

420

421

422

423

424

425

426

427

428

429

430

431

432

433

434

435

436

437

Matson, P.A., Parton, W.J., Power, A.G., Swift, M.J. 1997. Agricultural intensification and ecosystem properties. Science 277: 504-509.

Merow, C., Smith, M.J., Silander, Jr J.A. 2013. A practical guide to Maxent for modeling species' distributions: what it does, and why inputs and settings matter. Ecography, 36: 1058-1069.

Moffatt, M. 2020. Farming Post World-War II. Retrieved 18 June, 2020, from https://www.thoughtco.com/farming-post-world-war-ii-1146852.

Narouei-Khandan, H.A., Harmon, C.L., Harmon, P., Olmstead, J., Zelenev, V.V., van der Werf, W., Worner, S.P., Senay, S.D., van Bruggen, A.H.C. 2017. Potential global and regional geographic distribution of Phomopsis vaccinii on Vaccinium species projected by two species distribution models. European Journal of Plant Pathology 148: 919-930.

Narouei-Khandan, H.A., Worner, S.P., Viljanen, S.L., van Bruggenm A.H., Jones, E.E. 2020. Projecting the suitability of global and local habitats for myrtle rust (Austropuccinia psidii) using model consensus. Plant Pathology 69: 17-27.

Newton, A.C., Begg, G., Swanston, J.S. 2009. Deployment of diversity for enhanced crop function. Annals of Applied Biology 154: 309-322.

Numminen, E., Laine, A.L. 2020. The spread of a wild plant pathogen is driven by the road network. PLOS Computational Biology 16: e1007703.

Oosterbaan, R.J. 1989. Effectiveness and social/environmental impacts of irrigation projects. ILRI Annual Report 1988, 18-34.

Ortega-Huerta, M.A., Peterson, A.T. 2008. Modeling ecological niches and predicting geographic distributions: a test of six presence-only methods. Revista Mexicana de Biodiversidad 79: 205-216.

Osawa, T. 2015. Importance of farmland in urbanized areas as a landscape component for barn swallows (Hirundo rustica) nesting on concrete buildings. Environmental Management 55: 1160-1167.

Osawa, T., Mitsuhashi, H., Uematsu, Y., Ushimaru, A. 2011. Bagging GLM: Improved generalized linear model for the analysis of zero-inflated data. Ecological Informatics 6: 270-275.

Pegg, G.F., Brady, B.L. 2002. Verticillium wilts. CABI.

Peterson, A.T. 2014. Mapping Disease Transmission Risk: Geographic and Ecological Contexts.Baltimore, Maryland: Johns Hopkins University Press.

Peterson, A.T., Soberón, J., Pearson, R.G., Anderson, R.P., Martínez-Meyer, E., Miguel, Nakamura, M.B. Araújo. 2011. Ecological Niches and Geographic Distributions. Princeton, New Jersey: Princeton University Press.

Phillips, S.J., Dudik, M., Schapire, R.E. 2004. A maximum entropy approach to species distribution modeling. Proceedings of the 21st International Conference on Machine Learning. 655-662.

Phillips, S.J., Anderson, R.P., Schapire, R.E. 2006. Maximum entropy modeling of species geographic distributions. Ecological Modelling 190: 231-259. 
438 Radosavljevic, A., Anderson, P.R. 2014. Making better Maxent models of species distributions:

439

440

441

442

443

444

445

446

447

448

449

450

451

452

453

454

455

456

457

458

459

460

461

462

463

464

465

466

467

468

469

470

471

472

473

474

475 complexity, overfitting and evaluation. Journal of Biogeography, 41: 629-643.

Reicosky, D.C. 2003. Global environmental benefits of soil carbon management. In Conservation Agriculture, ed. L. García-Torres, J. Benites, A. Martínez-Vilela, A. Holgado-Cabrera, Heidelberg: Springer. 3-12

Sande, D., Mullen, J., Wetzstein, M., Houston, J. 2011. Environmental impacts from pesticide use: a case study of soil fumigation in Florida tomato production. International Journal of Environmental Research and Public Health 8: 4649-4661.

Shiraishi, T., Ohtuka, K., Sakai, H., Kemmochi, I., Shibata, S. 2000. Occurrence of Verticillium wilt of cabbage in Gunma prefecture. (In Japanese) Annual Report of the Kanto-Tosan Plant Protection Society 47: 53-54.

Soberón, J. 2007. Grinnellian and Eltonian niches and geographic distribution of species. Ecology Letters 10: 1115-1123.

Soberón, J., Peterson, A.T. 2005. Interpretation of models of fundamental ecological niches and species' distributional areas. Biodiversity Informatics: 1-10.

Syfert, M.M., Smith, M.J., Coomes, D.A. 2013. The effects of sampling bias and model complexity on the predictive performance of Maxent species distribution models. PloS ONE, 8.2: e55158.

Tilman, D., Cassman, K.G., Matson, P.A., Naylor, R., Polasky, S. 2002. Agricultural sustainability and intensive production practices. Nature 418: 671-677.

Tsushima, S., Yoshida, S. 2012. A new health-checkup based soil-borne disease management (HeSoDiM) and its use. FFTC-TUA Joint Symposium 2012. 13.

Tsushima, S. 2014. Integrated control and integrated pest management in Japan: the need for various strategies in response to agricultural diversity. Journal of General Plant Pathology 80: 389-400.

UC IPM. 2015. What is IPM. Retrieved 18 June, 2020, from https://www2.ipm.ucanr.edu/Whatis-IPM/\#DEFINITION

United Nations. 2015. World Population 2015. Retrieved24 June, 2020, from http://esa.un.org/unpd/wpp/Publications/Files/World_Population_2015_Wallchart.pdf

United States Environmental Protection Agency. 2017. Ozone Layer Protection. Retrieved 24 June, 2020 from http://www3.epa.gov/ozone/strathome.html

Village Office of Tsumagoi. 2017. Agriculture of Tsumagoi village. (In Japanease) Retrieved24 June, 2020, from http://www.vill.tsumagoi.gunma.jp/nougyou/index.html

Wang, R., Li, Q., He, S., Liu, Y., Wang, M., Jiang, G. 2018. Modeling and mapping the current and future distribution of Pseudomonas syringae pv. actinidiae under climate change in China. PLoS ONE 13: e0192153.

Wilhelm, S., Paulus, A.O. 1980. How soil fumigation benefits the California strawberry industry. Plant Disease 64: 264-270. 
Figure 1

Location of study area.

This study was conducted in Tsumagoi village ( $\left.36^{\circ} 51^{\prime} 17^{\prime \prime} \mathrm{N}, 138^{\circ} 53^{\prime} 00^{\prime \prime E}\right)$ of Gunma Prefecture in central Honshu, the largest of Japan's four main islands.

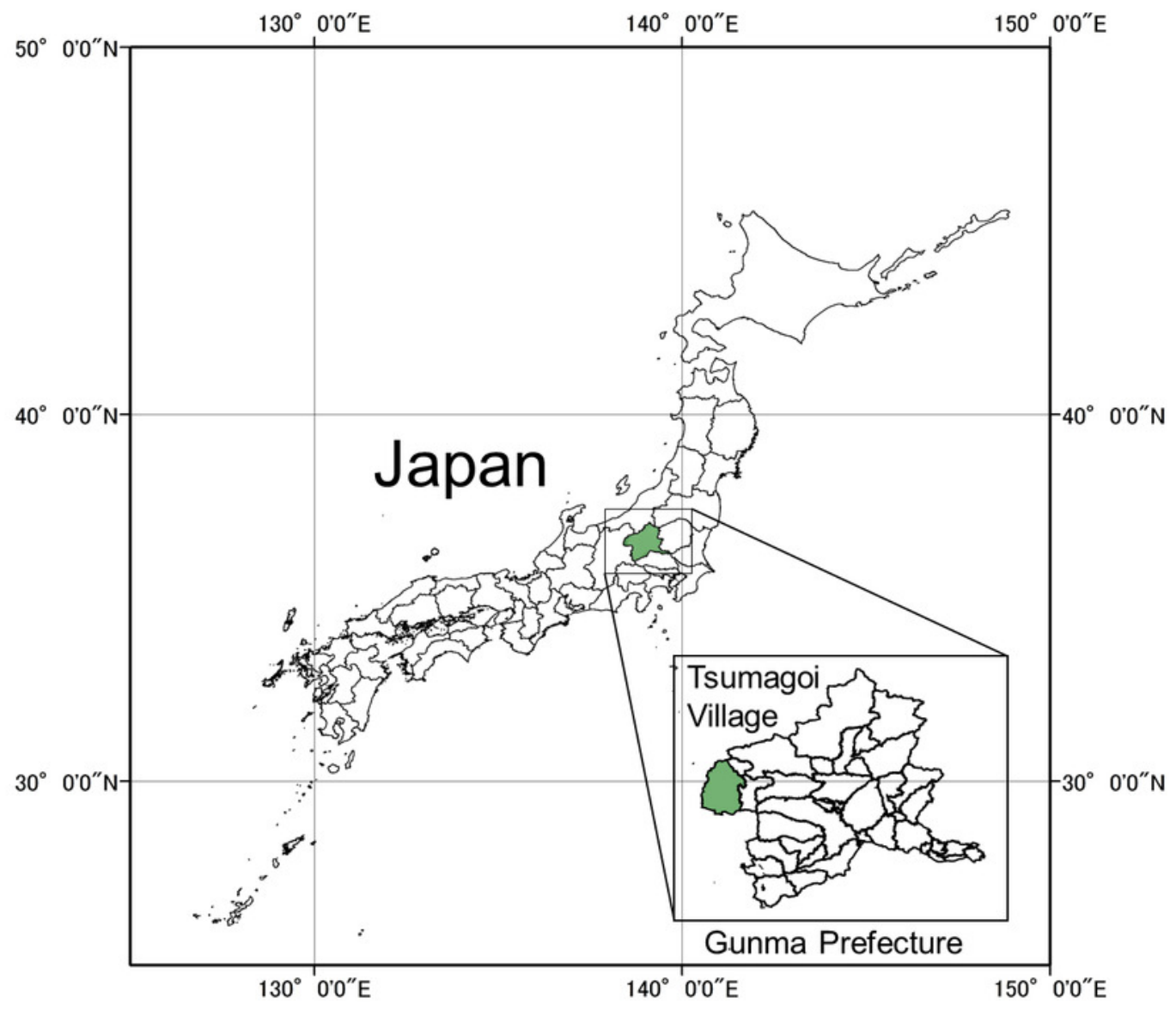


Figure 2

Symptoms of cabbage Verticillium wilt.

(A), (B) Leaves wilting and yellowing (C) Browning vascular systems.

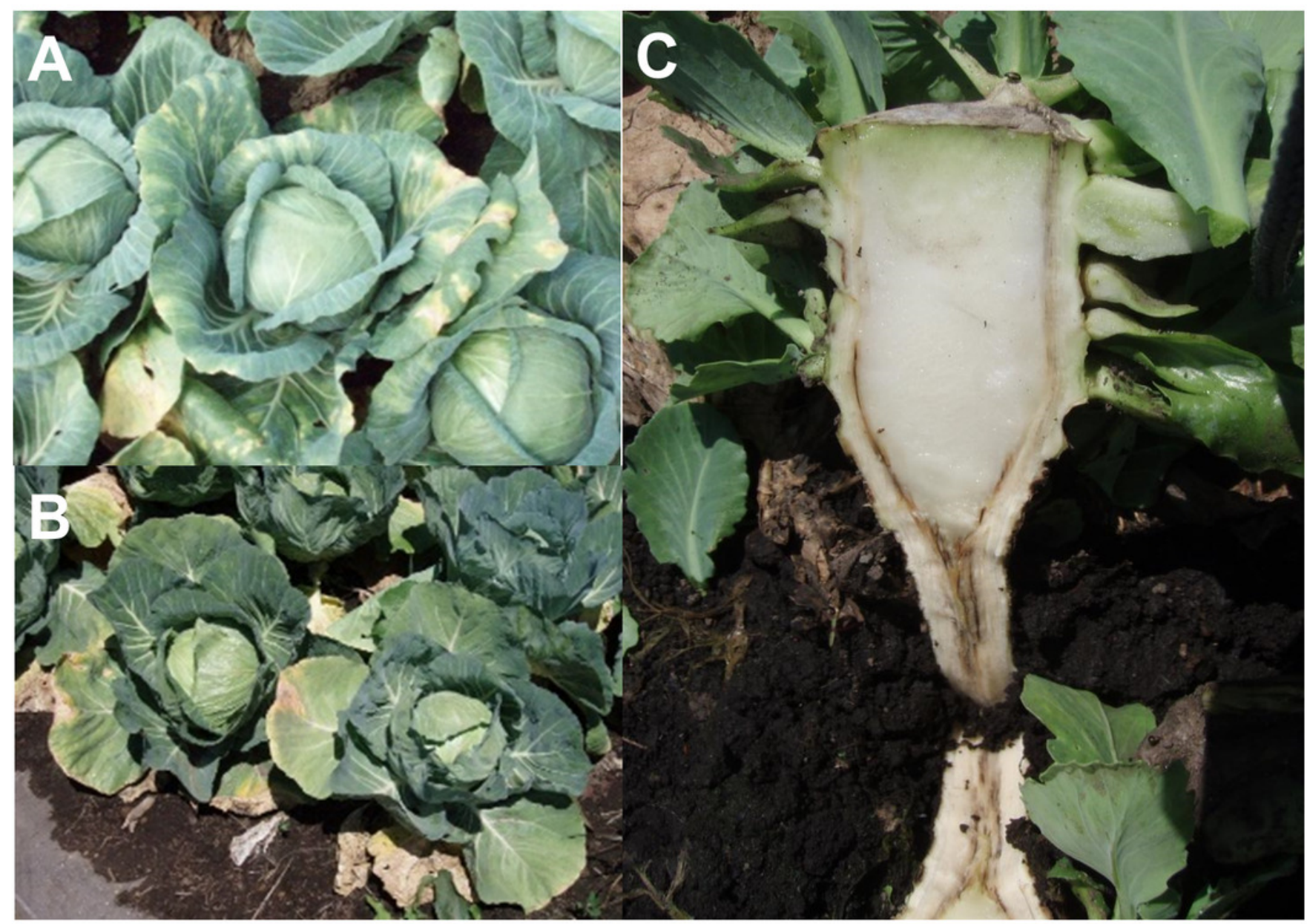


Figure 3

Agricultural area in study area and disease occurrence.

Each grid cell is $500 \times 500 \mathrm{~m}$. (A) agricultural area in Tsumagoi village, (B) occurrence of Verticillium wilt of cabbage in grid cells Base maps, including grid map, and distribution data of agricultural area were obtained from Fundamental Geospatial Data (Geographical Survey Institute; http://www.gsi.go.jp/kiban/, accessed on 6 January 2016) and National Land Numerical Information download service (Ministry of Land, Infrastructure, Transport and Tourism, http://nlftp.mlit.go.jp/ksj/, accessed on 6 January 2016), respectively.
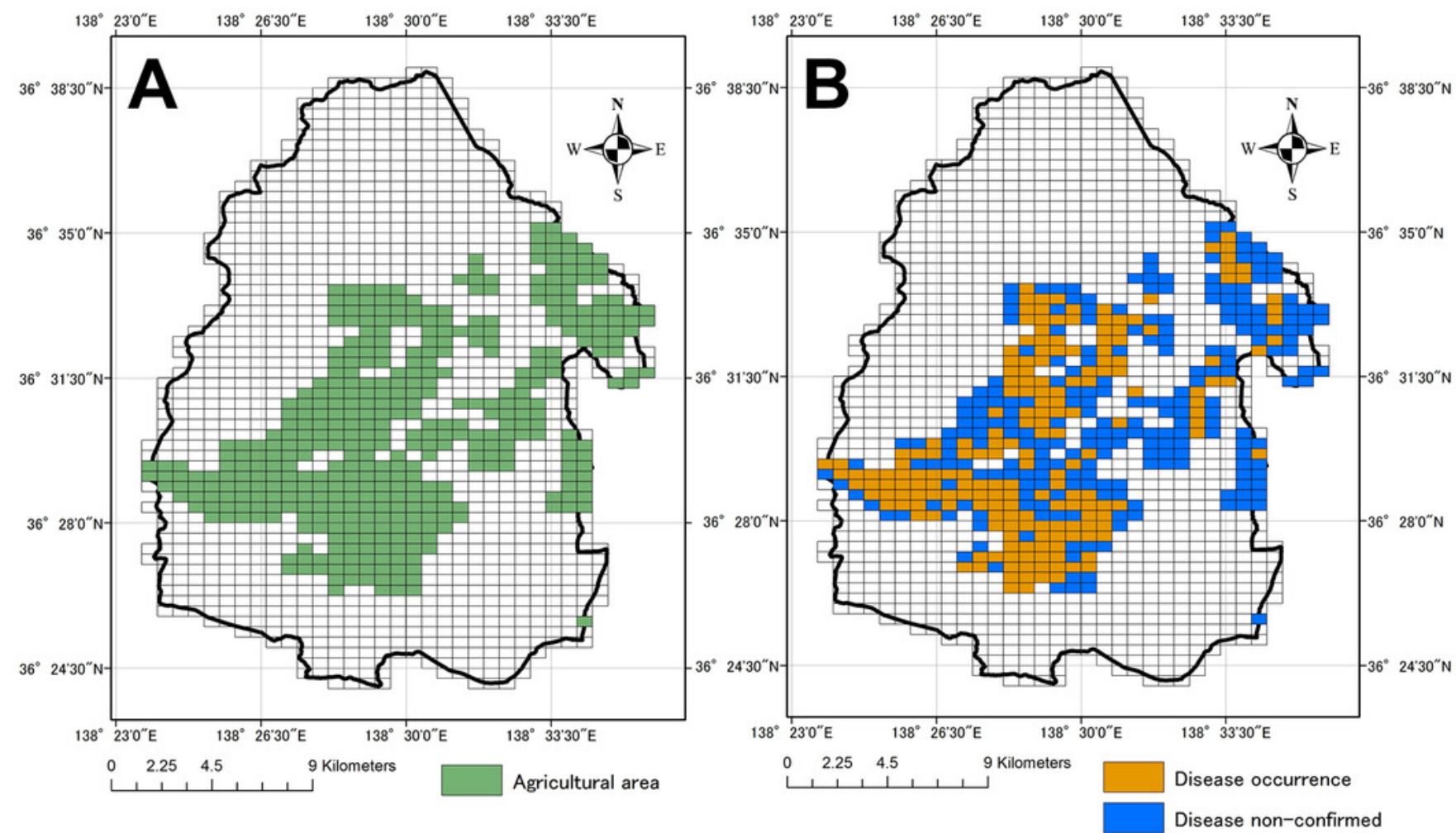
Figure 4

Distribution of occurrence probability of Verticillium wilt.

Each grid cell is $500 \times 500 \mathrm{~m}$. (A) Distribution map of occurrence probability of the disease;

(B) distribution map with the disease occurrence grids. Cells with a bold outline indicate disease occurrence. The occurrence probability in each grid was calculated based on disease occurrence data and 4 explanatory variables (road density, elevation, slop and topological wetness index) using by MaxEnt Ver. 3.3.3k (downloaded at:

https://www.cs.princeton.edu/ schapire/maxent/).

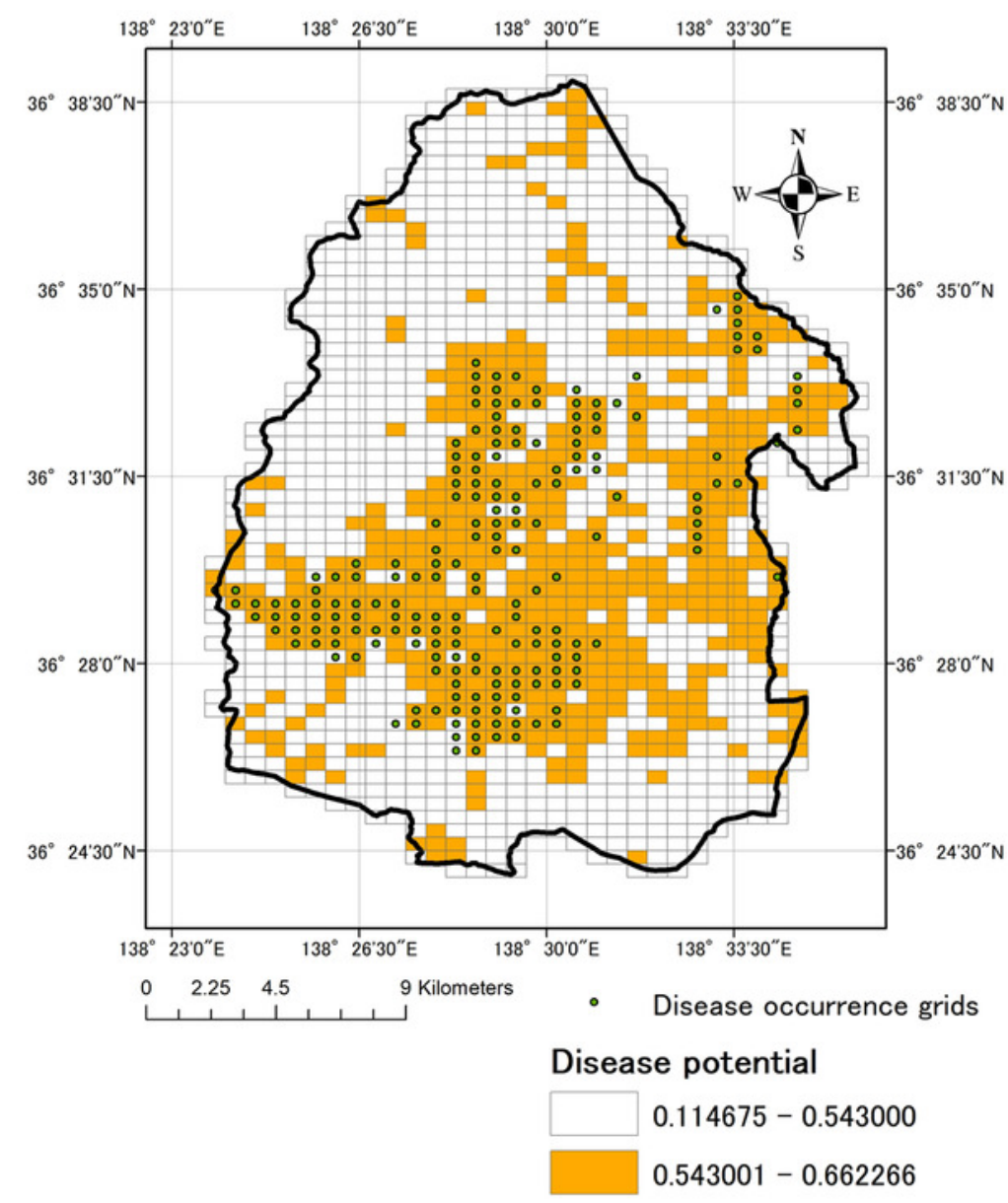


Figure 5

Marginal response curve between the disease potential occurrence calculated by MaxEnt and road density.

Blue band shows standard deviation.

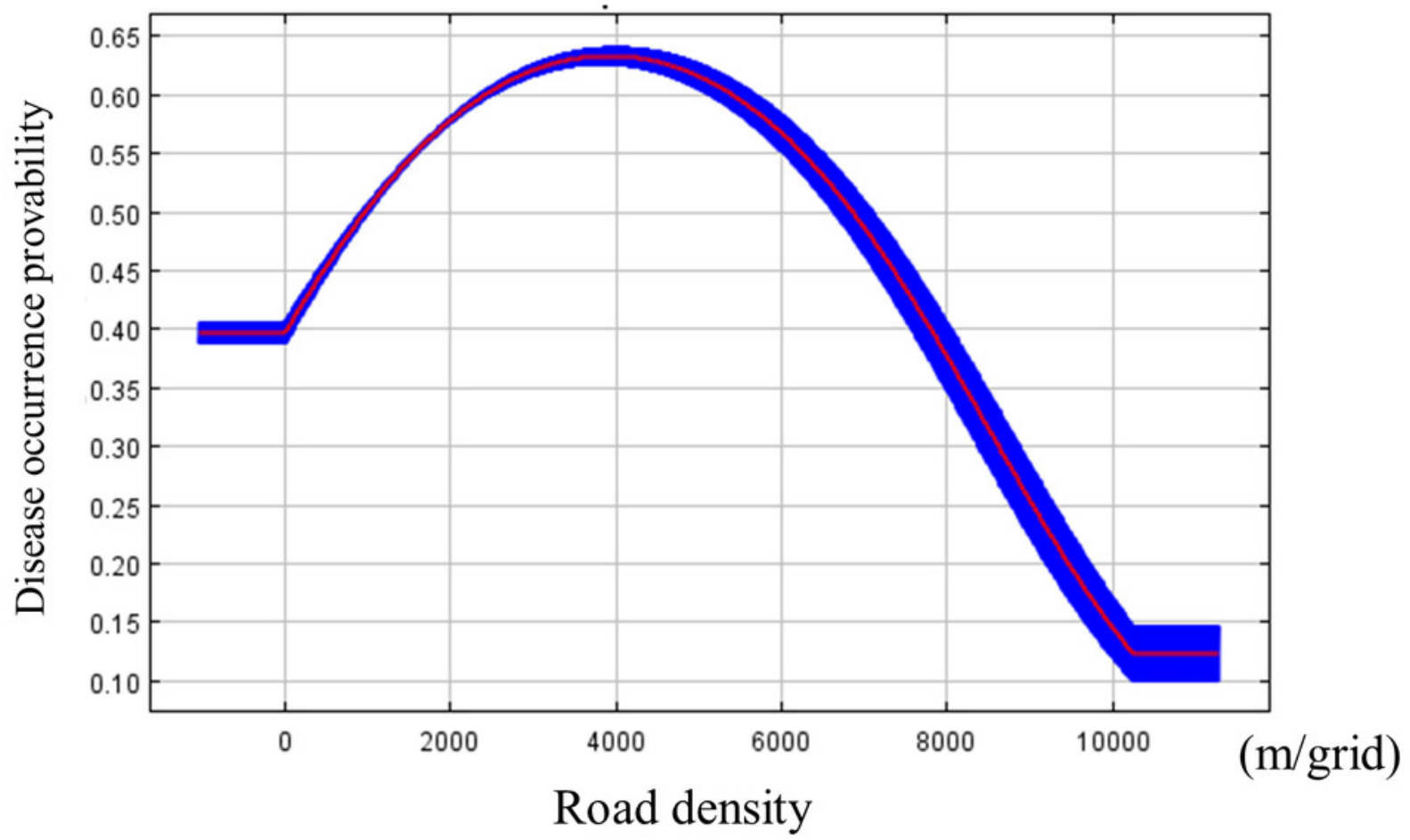




\section{Table $\mathbf{1}$ (on next page)}

Percent contribution and permutation importance of various variables in MaxEnt modering of cabbage Verticillium wilt. 
Table 1 Percent contribution and permutation importance of various variables in MaxEnt modeling of cabbage Verticillium wilt.

\begin{tabular}{lrr}
\hline Variables & Percent contribution & Permutation importance \\
\hline Road $(\mathrm{m})$ & 97.1 & 93.0 \\
TWI & 2.3 & 7.0 \\
Elevation $(\mathrm{m})$ & 0.5 & 0.0 \\
\hline
\end{tabular}




\section{Table 2(on next page)}

Evaluation indices of estimation accuracy in MaxEnt modeling of cabbage Verticillium wilt. 
Table 2 Evaluation indices of estimation accuracy in MaxEnt modeling of cabbage Verticillium wilt.

\begin{tabular}{lr}
\hline Evaluation indices & Values \\
\hline Area Under Curve (AUC) & 0.861 \\
Threshold by Maximum training sensitivity plus specificity & 0.543 \\
Correctly Classified Instances (CCI) & 0.705 \\
Sensitivity & 0.876 \\
Specificity & 0.678 \\
True Skill Statistics (TSS) & 0.554 \\
\hline
\end{tabular}

